\title{
Glycemic index values of traditional Kenyan foods: the missing link in the effectiveness of dietary approach in the prevention and management of diabetes mellitus in Kenya
}

\author{
Rebecca Ebere ${ }^{1}$, Jasper Imungi ${ }^{2}$, Violet Kimani ${ }^{3}$
}

1. Meru University of Science and Technology, Department of Food Science.

2. University of Nairobi, Department of Food Nutrition and Technology.

3. University of Nairobi, School of Public Health.

\begin{abstract}
:
Background: Glycemic index (GI) measures postprandial blood sugar after consumption of carbohydrate-rich foodstuff. Kenya is yet to fully embrace this concept in prevention and management of diabetes mellitus.

Objective: To review and tabulate GIs of locally consumed foods in order to improve dietary management of diabetes mellitus.

Methodology: A literature search was conducted using Google scholar and PubMed databases which identified 7 articles on glycemic index values of Kenyan foods published between 2002 and 2020. Two articles failed to meet the inclusion criteria and five proceeded for review. Key search words used included GI, glycemic load and glycemic response combined with Kenya. The data was reported depending on whether the testing involved healthy individuals or patients suffering from diabetes mellitus.

Results: Nine individual foods and 7 mixed meals were identified. Low GI foods included beans and whole maize ugali consumed alongside cowpea leaves. High GI foods included whole maize ugali eaten with beef, boiled rice, boiled cassava and cassava-sorghum ugali eaten with silver fish.

Conclusion: Proper meal mixing is important in diabetes management. Cowpea leaves and beans possess GI lowering potential. This information can be used to improve guidance on food choices for diabetes patients.

Keywords: Glycemic index, glycemic load and glycemic response, Kenya.

DOI: https://dx.doi.org/10.4314/ahs.v21i2.29

Cite as: Ebere R, Imungi J, Kimani V. Glycemic index values of traditional Kenyan foods: the missing link in the effectiveness of dietary approach in the prevention and management of diabetes mellitus in Kenya. Afri Health Sci. 2021;21(2). 710-718. https: / dx.doi.org/ 10.4314/ abs.v21i2.29
\end{abstract}

\section{Introduction}

This paper is addressing itself to the nutritional challenge faced by the dietary approach in the prevention and management of diabetes mellitus in Kenya. Diabetes mellitus is a chronic medical condition in which a person's sugar level rises above normal. If left uncontrolled, the excess sugar may damage the nerves and blood vessels resulting in amputation, blindness, renal failure, infertility in men, heart disease and stroke ${ }^{1}$.

Diabetes mellitus is prevalent worldwide. In the year 2019 the global prevalence of diabetes was estimated to be $9.3 \%$ (463 million people), this was projected to rise to $10.2 \%$ (578 million) and $10.9 \%$ (700 million) by the years 2030 and 2045 respectively $^{2}$. In the year 2015 an estimated 1.6 million people died from diabetes in

\section{Corresponding author:}

Rebecca Ebere,

Meru University of Science and

Technology, Department of Food Science.

Email: rebekaebere@yahoo.com
Kenya ${ }^{3}$. In 2016, non-communicable diseases including diabetes mellitus accounted for about $27 \%$ of all deaths in the country ${ }^{4}$.

There are many risk factors for diabetes mellitus including genetics ${ }^{5}$, lack of physical exercise, excessive consumption of alcohol and smoking of cigarettes ${ }^{6}$. Diabetes management aims at keeping glucose levels in the blood closer to the normal level as much as possible. Dietary approach has been clinically adopted in the prevention and management of diabetes to ensure healthy blood sugar level ${ }^{7}$. In addition to dietary approach, exercise and use of treatment drugs are also widely applied ${ }^{8}$. However many diabetic patients cannot afford the treatment due to the high cost resulting in complications and high mortality ${ }^{9}$. In addition, management of diabetes also involves limiting alcohol consumption; avoiding cigarette smoking; regular monitoring for associated complications involving eyes and feet, blood sugar, blood pressure as well as risks for kidney and cardiovascular diseases ${ }^{10}$. Kenya government is facing a number of challenges in prevention and management 
of diabetes. These include limited resources, a shortage of adequately trained healthcare personnel and lack of necessary equipment subsequently leading to lack of awareness and routine screening ${ }^{11}$.

Dietary approach to the prevention and management of type 2 diabetes is a common practice in Kenya although patients' adherence to recommendations still poses a challenge ${ }^{12}$. Current dietary prescription is mainly based on the amount of food served to diabetic patients, a macro-nutritional approach commonly known as the healthy diabetes plate, the plate method or simply "diabetic plate". It guides how much starchy food should be served in relation to non-starchy vegetables and proteins without considering how the meal affects postprandial blood sugar ${ }^{13}$. A key shortcoming with such an approach is the fact that carbohydrate-rich foods differ in postprandial blood sugar response. This means that a similar amount of different foodstuff cause different responses in terms of postprandial blood sugar. For example, 50g available carbohydrate from cassava is different from $50 \mathrm{~g}$ available carbohydrate from sweet potato in their potential to raise blood sugar levels ${ }^{14}$.

Glycemic index (GI) has widely been used to measure blood sugar responses after consumption of a carbohydrate-rich food in order to take into account such differences. GI is computed by dividing the area under the blood glucose response curve above the fasting blood sugar level after consuming $50 \mathrm{~g}$ available carbohydrates from a test food by area under the blood glucose response curve above the fasting level after consuming 50 $\mathrm{g}$ available carbohydrates from a standard or reference food and multiplying the resulting value by 100 . White bread or glucose are used as reference/standard foods and they are normally assigned a GI of $100{ }^{15}$. Thus foods have been categorized into low $(<55)$, medium (55-70) and high (>70) GI with glucose as a standard or values of $<60,60-85$ and $>85$ representing low, medium and high GI respectively with white bread as a standard/reference food ${ }^{16}$. High GI foods result in a greater blood glucose response and long-term consumption may lead to type 2 diabetes ${ }^{17}$ as opposed to low GI foods ${ }^{7}$. However, consuming a high GI food alongside a low GI food or other accompaniment has been shown to reduce the overall blood glucose response of a high GI food. For example the GI of rice has been reduced by beans ${ }^{18,19}$.

It is important to note that even low GI foods can result in higher blood glucose response and high GI foods may cause low response after consumption depending on the quantity of food consumed. This is better explained by glycemic load (GL) which accounts for both the quality as measured using GI and the amount of food consumed. GL is computed as follows; GL = GI/100 x available carbohydrates (total dietary carbohydrates - dietary fiber). Using this approach, foods can be classified into low (1-10), medium (11-19) and high $(\geq 20) \mathrm{GL}^{16}$ and this concept allows the right amount of food to be served for effective management of blood sugar.

Without taking into consideration the GI of the foods, there is a possibility of putting a diabetic person at risk of spiking their blood sugar using the macronutrient approach to management of diabetes. The GI of foods can however be manipulated in various ways to suit the needs of people suffering from diabetes mellitus. For example the GI has been found to vary depending on the nature of carbohydrates ${ }^{20}$, dietary fiber, ${ }^{21,22,23}$, other macronutrients present in the diet ${ }^{21,24,25}$, presence of micronutrients ${ }^{24}$, preparation, processing and storage ${ }^{20,}$ 26,27 , botanical origin and variety $17,18,28,29,30,31$, presence of phytochemical ${ }^{28,32}$ as well as an accompaniment to the staple or mixing different foods into meals ${ }^{18,19}$.

Despite the advantage posed by GI, adequate information on GI values of most traditional foods consumed by Kenyans is missing. This creates a challenge for the practitioners with regard to the selection of the appropriate diet for diabetics. The available international table of glycemic indices of foods ${ }^{7,33}$ currently being adopted in selecting the diet for diabetics is limited in terms of the commonly consumed Kenyan foodstuff. As a way of preventing and managing diabetes through a dietary approach, it is important to identify and promote consumption of culturally acceptable, locally available and affordable staple foods ${ }^{34}$. This paper therefore, reviewed glycemic indices of various traditional carbohydrate-rich foods consumed in Kenya with an aim of improving the knowledge base and the possibility of increasing their utilization in the prevention and management of diabetes mellitus.

\section{Methodology}

An electronic database literature search was conducted on Pubmed and Google Scholar on studies published between 2002 when the first international Table of glycemic index values was published 7 to April 2020. Inclusion criteria were studies published in English, involving human studies and following standardized methods. 
Exclusion criteria were studies not published in English, in vitro studies, those involving animals and those that did not follow standard methods ${ }^{33}$. The search terms included glycemic index, glycemic load and glycemic response combined with Kenya. Glycemic index values listed in previous tables ${ }^{7}$ were also included.

Final data were divided into two tables comprising of values derived from healthy subjects and values derived using individuals suffering from type 2 diabetes mellitus. To ensure uniformity in presentation of results, those presenting values in mean \pm SD had the standard deviation value divided by square root of sample size to present all the results as mean $\pm \mathrm{SE}$. Values that were tested using white bread as a reference and then converted to glucose scale do not indicate the SE. Values that were tested used white bread as a reference and then converted to glucose scale do not indicate the SE. Results of available carbohydrate are presented on dry weight basis unless otherwise indicated against the foodstuff. Also, since both glucose and white bread are used as reference foods, a conversion factor of $70 / 100$
(0.7) was used to convert from white bread scale to glucose scale. Hence the glucose scale has been used for final reporting as recommended to avoid possible confusion in the interpretation of the results ${ }^{7,33}$. Carbohydrate content was obtained from the reference papers. GL values were calculated as the product of the amount of available carbohydrate in a specified serving size and the GI value (using glucose as the reference food), divided by $100^{7,33}$.

\section{Results}

Glycemic index values cereal-based individual foods/ meals tested on healthy individuals follow the order: boiled white rice $>$ whole maize ugali with beef $>$ whole maize ugali with silver fish $=$ rice with beef $>$ whole maize ugali (plain) $=$ rice with beans $>$ whole maize ugali; cowpea leaves. Bean stew had a GI of 44 while roots and tubers' products followed the following order: cassava -sorghum ugali with silver fish $>$ boiled cassava $>$ Cassava-sorghum ugali with cowpea leaves $>$ sweet potato. Low GI was observed in beans and whole maize

Table 1: Glycemic indices of some Kenyan foods tested on healthy individuals ( $\mathrm{n} \geq 7$ )

\begin{tabular}{|c|c|c|c|c|}
\hline $\mathbf{S} / \mathbf{N}$ & Food type & $\begin{array}{l}\text { Available } \\
\text { carbohydrate } \\
(\% \text { dwb) }\end{array}$ & $\begin{array}{l}\text { Serving size } \\
\text { (g) } \\
\text { containing } \\
50 g \\
\text { carbohydrate } \\
\text { (wwb) } \\
\end{array}$ & $\begin{array}{l}\text { GI (mean } \pm \text { SE) } \\
\text { Ref: glucose }\end{array}$ \\
\hline \multicolumn{5}{|c|}{ Cereal-based products } \\
\hline 1 & Whole maize ugali; plain & $92.09 \pm 0.27$ & 160 & $62 \pm 8.90$ \\
\hline 2 & Whole maize ugali; silver fish & $92.09 \pm 0.27$ & $148 ; 30$ & $69.1 \pm 10.00$ \\
\hline 3 & Whole maize ugali, cowpea leaves & $\begin{array}{l}92.09 \pm 0.27 \\
18.86 \pm 0.05\end{array}$ & $158 ; 50$ & $45 \pm 6.60$ \\
\hline 4 & Whole maize ugali; beef & $\begin{array}{l}92.09 \pm 0.27 \\
\text { Assumed } 0\end{array}$ & $160 ; 150$ & $71 \pm 6.70$ \\
\hline 5 & $\begin{array}{l}\text { Boiled white } \\
\text { rice (mwea pishori) }\end{array}$ & $25.98 \pm 0.12 \mathrm{wwb}$ & 192 & $77 \pm 5.69$ \\
\hline 6 & Rice (mwea pishori); beef & $\begin{array}{l}25.98 \pm 0.12 \mathrm{wwb} \\
\text { Assumed } 0\end{array}$ & $192 ; 150$ & $69 \pm 7.70$ \\
\hline 7 & $\begin{array}{l}\text { Rice; beans } \\
\text { Mwea pishori rice; rose coco beans }\end{array}$ & $\begin{array}{l}25.98 \pm 0.12 \mathrm{wwb} \\
16.03 \pm 0.15 \mathrm{wwb}\end{array}$ & $142 ; 80$ & $62 \pm 5.16$ \\
\hline \multicolumn{5}{|c|}{ Legumes } \\
\hline 1 & Bean stew & $16.03 \pm 0.15 \mathrm{wwb}$ & 312 & $44 \pm 10.00$ \\
\hline \multicolumn{5}{|c|}{ Roots and tubers' products } \\
\hline 1 & Sweet potato & $90.04 \pm 0.03$ & 168 & $64.54 \pm 7.11$ \\
\hline 2 & Boiled cassava & $78.81 \pm 0.45$ & 175 & $74.10 \pm 6.31$ \\
\hline 3 & $\begin{array}{l}\text { Cassava-sorghum ugali; cowpea } \\
\text { leaves }\end{array}$ & $\begin{array}{l}91.79 \pm 0.12 \\
18.86 \pm 0.05\end{array}$ & $164 ; 50$ & $69 \pm 9.01$ \\
\hline 4 & Cassava-sorghum ugali; silver fish & $\begin{array}{l}91.79 \pm 0.12 \\
34.45 \pm 0.0 \\
\end{array}$ & $157 ; 30$ & $83 \pm 12.01$ \\
\hline
\end{tabular}


ugali consumed alongside cowpea leaves. These results are shown in Table 1.
For the specific foods tested on individuals suffering from type 2 diabetes mellitus, the order of GI values was as follows: boiled white rice>maize meal por-

Table 2: Glycemic indices of some Kenyan foods tested on individuals who were suffering from type 2 diabetes mellitus ( $\mathrm{n} \geq 7)$.

\begin{tabular}{|c|c|c|c|c|}
\hline $\mathbf{S} / \mathbf{N}$ & Food type & $\begin{array}{l}\text { Available } \\
\text { carbohydrate }\end{array}$ & $\begin{array}{l}\text { Serving size (g) } \\
\text { containing 50g } \\
\text { carbohydrate }\end{array}$ & $\begin{array}{l}\text { GI (mean } \pm \text { SE) } \\
\text { Ref: glucose }\end{array}$ \\
\hline \multicolumn{5}{|c|}{ Cereal-based products } \\
\hline 1 & $\begin{array}{l}\text { Boiled white rice } \\
\text { (unspecified variety) }\end{array}$ & $\begin{array}{l}42 \mathrm{~g} \text { available } \\
\text { carb/150g } \\
\text { serving }\end{array}$ & 150 & 112 \\
\hline 2 & Maize meal porridge/ gruel & $38 / 50 \mathrm{~g}$ & $50 \mathrm{~g}$ (dry) & 109 \\
\hline 3 & Millet flour porridge/ gruel & unspecified & unspecified & 107 \\
\hline \multicolumn{5}{|c|}{ Roots } \\
\hline 4 & Cassava, boiled, with salt & $27 \mathrm{~g} / 100 \mathrm{~g}$ & 100 & 46 \\
\hline
\end{tabular}

ridge $>$ millet flour porridge $>$ boiled and salted cassava. These results are shown in Table 2 .

\section{Discussion}

Kenyan population consumes a variety of foods including snacks, thin porridges (uji), dishes from rice, maize, legumes, meat, fish, eggs, poultry, blood dishes, vegetable, roots and bananas, stiff porridge (ugali), flat bread (chappati), mashed dishes, deserts and sauces. Staple food is mainly maize and other cereal grains such as rice, wheat, millet and sorghum depending on the region. These staples are usually consumed alongside a variety of meats, legumes and/or vegetables ${ }^{36}$.

\section{Glycemic index of cereal-based food products/ meals}

The predominant cereals consumed by the Kenyan population include maize (Zea mays), rice (Oryza sativa) and wheat (Triticum aestivum $)^{37}$. Maize is consumed in the form of a thin (uji) or stiff/thick (ugali) porridge. The stiff porridge is usually consumed alongside an accompaniment ${ }^{18,35,36}$. The same applies to many rice and wheat products ${ }^{36}$. Whole milled maize, sorghum (Sorgum bicolor) and finger millet (Eleusine coracana) have been recommended in some parts of the country for preparing ugali (stiff porridge) and uji (thin porridge) for people suffering from non-communicable diseases including type 2 diabetes mellitus but also plain cassava alone or mixed with finger millet, sorghum or both can be used to prepare ugali ${ }^{38}$.

A moderate GI of 62 has been reported in a study conducted on healthy individuals in Kenya (Table 1). A GI of 94 was reported for stiff porridge from Malawi which has a moisture content of $76.54 \%$ as opposed to $66 \%$ in the Kenyan study ${ }^{39,40,41}$ which may have influenced the extent of starch gelatinization. Processing methods have been found to influence the GI ${ }^{42,43}$. For instance, cooking in excess water resulted in a higher rate of starch digestion while cooking in limited water may allow starch granules to rearrange and interact together limiting the rate of digestion ${ }^{43}$. Whole maize ugali consumed in Tanzania had a GI of $71^{44}$. The differences in GI could also be as a result of possible differences in maize varieties ${ }^{32}$ which were not documented in these studies. The possible differences in varieties would also mean differences in amylose to amylopection ratio which influence formation of resistant starch and consequently starch digestibility ${ }^{20}$. In addition, similar foods made from flour milled by different methods have been found to vary in terms of $\mathrm{GI}^{27}$. The particle sizes and milling methods were not documented in these studies.

As opposed to silver fish (Rastrineobola argenteus) and beef, cowpea leaves (Vigna unguiculata) lowered the glycemic index of whole maize meal ugali. A low GI of 45 was reported. Cowpea leaves contain significant amounts of protein, fiber, prebiotics, fat, iron, calcium, phosphorus, magnesium, iodine, potassium and sodium $^{45,}{ }^{46}$. In addition, cowpea leaves contain phytochemicals including polyphenols, tannins, saponins and flavonoids ${ }^{46}$. Most of these components have been associated with lower GI, for example magnesium ${ }^{47}$, polyphenols ${ }^{32}$, and tannins ${ }^{48}$. In addition, dietary fiber and magnesium intakes may have reduced insulin resistance ${ }^{49}$. Generally a low GI diet has been associated with 
high intakes of micronutrients, fat and sodium ${ }^{24}$ as well as other macromolecules present in the $\operatorname{diet}^{22,29}$.

Apart from cowpea leaves, other vegetable dishes that can be consumed alongside ugali and whose impacts on GI are yet to be determined include stir fried kales; cabbage; jute mallow and pumpkin leaves; pumpkin leaves; spider plant, amaranth and African nightshade leaves; vine spinach; stir-fried amaranth leaves; mashed pumpkin and African nightshade leaves; stinging nettle leaves; stewed cowpeas leaves and jute mallow leaves; stir-fried spinach; sweet potato leaves; stewed mushrooms in peanut butter; potato curry; peas and brinjal curry ${ }^{36}$. On the other hand consumption of ugali accompanied by beef or silverfish popularly known as omena in Kenya, resulted in an increased glycemic index of 69 (Table 1). Although both were rich in protein which reduce postprandial glucose response ${ }^{25}$ and fat that also lowers the $\mathrm{GI}^{24}$ the GI was increased. This could be explained by the fact that the amount of ugali in relation to accompaniment is usually large. The large proportion of carbohydrates could have outweighed the GI lowering effect of protein or fat ${ }^{22}$. In addition, beef has been associated with decreased insulin sensitivity ${ }^{50}$.

The impact of the following meat, fish and egg dishes on GI of ugali has not yet been documented: stir fried goat meat; stir fried beef; Swahili spiced beef stew; minced meat balls; stewed dried fish; fried tilapia; Hydrabadi biryani; stewed Nile perch; stewed goat meat; camel meat; sheep tail fat; beef, maize and wheat flour mix; okra meat dish. In addition the effect on GI of sautéed termites, fried egg, omelette, Spanish omelette and poultry including stewed chicken; fried chicken; stewed quails and stewed guinea fowl as well as blood dishes including cow blood, beef and cow fat; cow blood with sour milk; blood cooked in fresh milk; fresh blood and fresh milk ${ }^{36}$.

Aside from ugali prepared from whole maize flour, ugali can also be prepared from maize and finger millet flour; maize, red sorghum and finger millet flour; refined maize flour; red sorghum, maize and finger millet flour; cassava flour; cassava, finger millet and sorghum flour; finger millet flour as well as banana and maize flour. Ugali can also be prepared from any of these flours and cooked using sour milk instead of water ${ }^{36}$. The GI of these preparations is yet to be determined. The GI of gruel/thin porridge (uji) prepared from maize meal porridge and millet meal was 109 and 107 respectively (Table 2 ). However it is important to note that these were results conducted on individuals suffering from type 2 diabetes mellitus. A recent study conducted on glycemic responses from gruel prepared from finger millet and white maize flours did not find significant difference between the two samples in terms of postprandial glycemic response although this study did not calculate the GI of these samples ${ }^{51}$. Other cereal-based products with unknown GI and are usually consumed alongside same accompaniments as ugali and rice include wheat products such as white chapati, brown chapati, roti (Indian chapati) and bhature (fried Indian bread). The GI is also yet to be determined for the following maize dishes: ashir; fresh beans and maize; dried maize and beans; sautéed maize and beans; dehulled maize and beans; crushed maize ${ }^{36}$.

Plain boiled white rice had a GI of 77 which was lowered to 69 and 62 when consumed with beef and beans respectively (Table 1). The unspecified white rice variety had a GI of 112 tested on type 2 diabetes patients (Table 2). The difference could be attributed to the different rice varieties ${ }^{29,31}$ and possibly between starches obtained from different locations ${ }^{52}$. In addition, the unspecified white rice variety in Table 2 could also be from the fact that the test participants were diabetes patients ${ }^{53}$. Both beef and beans lowered the GI probably due to their protein content ${ }^{21,25}$. The protein source could also be playing a significant effect with better effect observed from proteins of plant origin ${ }^{54}$. In addition, the GI lowering effect from beans could be resulting from presence of fiber ${ }^{21,55,56}$, polyphenols ${ }^{57}$ or resistant starch and the beans cell walls which modulate starch gelatinization thereby reducing enzymatic hydrolysis ${ }^{58}$. In addition beans being a lente-carbohydrate possess a low GI which could have diluted high GI of rice.

Rice dishes with unknown GI include spiced rice (pilau), Swahili biryani rice, onion fried rice, potatoes in rice, steamed rice and rice with milk. Rice in Kenya can be consumed alongside same accompaniments discussed above for ugali. Other cereal-based products with unknown GI and are usually consumed alongside same accompaniments as ugali and rice include wheat products such as white chapati, brown chapati, roti (Indian chapati) and bhature (fried Indian bread). The GI is also yet to be determined for the following maize dishes: ashir; fresh beans and maize; dried maize and beans; sautéed maize and beans; dehulled maize and beans; crushed maize ${ }^{36}$.

\section{Glycemic index of legumes}

The GI of beans was 44 (Table 1). The factors that could have contributed to the low GI of beans have been discussed above alongside rice and beans meal. Other legume dishes whose GI data is still missing in- 
clude lentil stew; green gram stew; bean stew with milk and cream; black bean stew; pigeon peas stew; skinned bean stew; stewed split dal; chick peas curry; sautéed red kidney beans and red sorghum; red sorghum, beans and teff flour ${ }^{36}$. These stews can be consumed alongside ugali, rice or chapatti and their effect on GI of these staples is yet to be documented in Kenya.

\section{Glycemic index of roots and tubers products}

In a study conducted on healthy individuals, the GI of sweet potato (Ipomoea balatas L.) was 65 and that for cassava (Manihot esculenta Crantz) was 74 although the two values were not found to be statistically different (Table 1). Jamaican boiled sweet potato had a GI of range of $41 \pm 5$ to $50 \pm 3$ (SEM) in ten different varieties $^{59}$. The differences could be attributed to the origin or geographical location ${ }^{52,60}$. Bangladesh sweet potato recorded a GI of $191 \pm 66$ (SD) in a study conducted on individuals suffering from type 2 diabetes mellitus ${ }^{53}$. A GI of 74 reported in the Kenyan study with regard to cassava was high. This is in agreement with a Caribbean study conducted on healthy individuals that reported a GI of $94 \pm 11$ (SEM) ${ }^{26}$. Cassava boiled in salt and tested on individuals suffering from type 2 diabetes reported a GI of 46 although the portion size administered may not be equivalent to $50 \mathrm{~g}$ available carbohydrate. In addition a higher sodium intake has been associated with a low $\mathrm{GI}^{24}$ although higher salt intake may not be encouraged due to associated detrimental health effects. Cassava has also been used in preparation of ugali. This is usually from flour prepared using fermented and sundried cassava pieces mixed with either finger millet, sorghum or both ${ }^{36}$. Ugali prepared from cassava and sorghum consumed alongside cow pea leaves had a GI of 69 (moderate) while when consumed with silver fish the GI was 83.The effect of cowpea leaves and silver fish on GI have been discussed earlier with regard to whole maize meal ugali. In both scenarios cowpea leaves lower the GI as opposed to silver fish.

However differences can be noted between whole maize meal ugali and cassava-sorghum ugali with whole maize meal ugali having a lower GI when consumed with either cowpea leaves or silver fish. A study on sorghum chips reported a high GI $(>70)^{54}$ and this together with a high GI for cassava in the Kenyan study could partially explain the higher GI of ugali prepared from cassava-sorghum as opposed to that from whole maize meal. A separate study found most sorghum-based food products to have lower GI than their respective wheat or rice-based foods ${ }^{30}$. It is important in future studies to note the sorghum variety and the ratios used in composite flour. For example the ratio of sorghum to cassava flour used in preparation of ugali is usually very low ${ }^{18,38}$.

Other foods in this category whose GI is yet to be determined locally include arrowroots; yam stew; sweet potatoes with peanut butter; arrowroot stew; pan fried arrowroots; pan fried sweet potatoes; potato bhajia and potato chips as well as mashed dishes including fresh maize, potato and pumpkin leaves mash; maize, beans, potatoes and pumpkin leaves mash; black beans, green bananas and potatoes mash; green maize and sweet potatoes mash; sweet potatoes and de-hulled black beans mash; mashed cassava and pigeon peas; mashed potatoes; enriched mashed potatoes; mashed beans and potatoes; mashed sweet potato and black beans ${ }^{36}$.

\section{Other foods with unknown glycemic index}

In addition to the foods listed and discussed above, the GI of following foods is still missing include: green bananas and stewed green bananas with meat; mashed bananas plain; enriched mashed bananas; enriched matoke; pumpkins with peanut butter; fresh maize; potato and pumpkin leaves; mashed pigeon peas and green maize and common snacks (fried dumplings; Swahili doughnuts; enriched East African doughnuts; East African doughnuts; meat samosa; vegetable samosa; pancakes; drop scones; Qita; mkate kuta; egg toast; oatmeal; pumpkin and coconut milk). These common snacks are mostly consumed alongside mixed tea. Desserts and sauces (sweetened pumpkin and coconut milk; semolina and nuts; diluted yoghurt; groundnut sauce) ${ }^{36}$ could also impart on GI and their effect is not documented.

\section{Use of GI data in computing GL and appropriate food portion size in diabetes management}

As described earlier, foods can be classified into low (1$10)$, medium (11-19) and high ( $\geq 20)$ GL.

Consider an example of GI of beans (rose coco) which is estimated at 44

Using the formula: GL = GI/100 x Available carbohydrates.

Assuming the aim is to give a patient a glycemic load of 10 (low GL), what portion size should the patient be served?

$\mathrm{GL}=(44 / 100) \times$ Available carbohydrates

$10=0.44$ available carbohydrates

Available carbohydrates equivalent to a GL of $10=$ $22.72 \mathrm{~g}$

Available carbohydrate in beans was 16\% (wwb) 
Therefore to attain a GL of 10 , the serving portion size should be $(22.72 \times 100)$ divided by $16=142 \mathrm{~g}$ of beans.

\section{Conclusion}

Data on glycemic index values for Kenyan local foods is limited. This paper calls for the need to build a data base of the GI of traditional Kenyan foods. Various factors influencing GI especially of common staples should be exploited in dietary prevention and management of diabetes. These may include appropriate mixing of foods into meals taking into consideration the food types and ratios, processing/cooking methods as well as food variety.

Key recommendations in the application of dietary approach in prevention and management of diabetes in Kenya

1. GI of local foods should be determined and adopted as a key measure of nutritional quality of foods.

2. The public should be educated on the how to combine various foodstuffs into meals depending on their GI.

3. Various factors affecting the GI could be explored with a view of lowering the GI of common staple foods.

4. Policy makers should consider the inclusion of GI information on the existing book; "Kenyan Food Recipes, a Kenyan recipe book of common mixed dishes with nutrients values".

\section{Conflict of interest}

None declared.

\section{References}

1. A.D.A. American Diabetes Association. Diagnosis and classification of diabetes mellitus. Diabetes Care. 2004; 27:5-10.

2. Saeedi P, Petersohn I, Salpea P, Malanda B, Karuranga $\mathrm{S}$, Unwin $\mathrm{N}$, et al.. Global and regional diabetes prevalence estimated for 2019 and projections for 2030 and 2045: Results from the International Diabetes Federation Diabetes Atlas, 9th edition. Diabetes Research and Clinical Practice. 2019; 157: 107843.

3. WHO. World Health Statistics 2017: Monitoring health for the SDGs. https://www.who.int/gho/publications/ world_health_statistics/2017/EN_WHS2017_Part2. pdf?ua $=1$. Site accessed on 30th March, 2020. https// doi.org/10.1016/j.diabre.2019.107843.

4. WHO. World Health Organization - Non communicable Diseases (NCD) Country Profiles, 2018. https:// www.who.int/nmh/countries/ken_en.pdf?ua=1. Site visited on 30th March, 2020.

5. Herder $\mathrm{C}$ and Roden M. "Genetics of type 2 diabetes: pathophysiologic and clinical relevance". European Journal of Clinical Investigation. 2011; 41(6): 679-92.

6. Ripsin, C.M, Kang H and Urban RJ.'Management of blood glucose in type 2 diabetes mellitus". American Family Physicians. 2009; 79 (1): 29-36.

7. Foster-Powell K, Holt SHA and Brand-Miller JC. International table of glycemic index and glycemic load values: 2002. The American Journal of Clinical Nutrition. 2002; 76:5-56.

8. A.D.A American Diabetes Association. Diagnosis and classification of diabetes mellitus. Diabetes Care. 2010; 33(1):S62-9.

9. Hall V, Thomsen RW, Henriksen O and Lohse N. Diabetes in Sub Saharan Africa 1999-2011: epidemiology and public health implications A systematic review. Bio Med Central Public Health. 2011; 11:564.

10. International Diabetes Federation. IDF Diabetes Atlas, $8^{\text {th }}$ edn. Brussels, Belgium: International Diabetes Federation, 2017. http://www.diabetesatlas.org.

11. Mohamed SF, Mwangi M, Mutua MK, Kibachio J, Hussein A, Ndegwa Z, et al.. Prevalence and factors associated with pre-diabetes and diabetes mellitus in Kenya: results from a national survey. BMC Public Health. 2018. 18; 1215.

12. Musee CN, Omondi DO and Odiwuor W. Dietary Adherence Pattern in the Context of Type 2 Diabetic Management within Clinical Setting, Kenya. International Journal of Diabetes Research. 2016; 5(2): 26-34.

13. Raidl M, Spain K, Lanting R, Lockard M, Johnson S, Spencer M, et al. The healthy diabetes plate. Preventing Chronic Diseases serial online. 2007; 4(1):A12. Available from: http://www.cdc.gov /pcd/issues/2007/ jan/06_0050.htm.

14. Ebere RA, Imungi JK and Kimani VN. Glycemic responses of cassava and sweet potatoes consumed in Western Kenya. Food Science and Quality Management. 2017; 63: 7-12.

15. FAO/WHO. Carbohydrates in human nutrition, Report of a Joint FAO/WHO Expert Consultation. FAO Food Nutrition Paper. 1998; 66:1-140. www.fao. org/docrep/w8079e/w8079e00.htm

16. Augustin LSA, Kendall CWC, Jenkins DJA, Willet WC, Astrup A, Barclay AW et al. Glycemic index, glycemic load and glycemic response: An international scientific consensus summit from the international carbohydrate quality consortium (ICQC). Nutrition, Metabolism and Cardiovascular Diseases. 2015; 25(9):795-815.

17. Eleazu CO. The concept of low glycemic index and 
glycemic load foods as panacea for type 2 diabetes mellitus; prospects, challenges and solutions. African Health Sciences. 2016; 16(2), June 2016.

18. Ebere RA, Imungi JK and Kimani VN. Proximate composition, energy contents and blood sugar responses of stiff porridge and rice meals consumed in Kenya. Food Science and Quality Management. 2017; 63:64-73.

19. Winham, DM, Hutchins AM, Thompson SV. Glycemic Response to Black Beans and Chickpeas as Part of a Rice Meal: A Randomized Cross-Over Trial. Nutrients. 2017; 9, 1095.

20. Li Y, Zhanga AR, Luo HF, Wei H, Zhou Z, Peng J et al. In Vitro and in Vivo Digestibility of Corn Starch for Weaned Pigs: Effects of Amylose:amylopectin Ratio, Extrusion, Storage Duration, and Enzyme Supplementation. Journal of Animal Science. 2015; 93 (7), 3512-20.

21. Bonnema AL, Altschwager DK, Thomas W, Slavin JL. The effects of the combination of egg and fiber on appetite, glycemic response and food intake in normal weight adults - a randomized, controlled, crossover trial. International Journal of Food Sciences and Nutrition. 2016; 67(6):723-731.

22. Hettiaratchi UPK, Ekanayake S and Welihinda J. Glycaemic indices of 03 Sri-Lankan wheat bread varieties and a bread-lentil meal. International Journal of Food Science and Nutrition. 2009; 60(S4):21-30.

23. Widanagamage R, Ekanayake $\mathrm{S}$ and Welihinda J. Carbohydrate rich foods: glycaemic indices and correlation with macronutrients. International Journal of Food Science and Nutrition. 2009a; 60(S4):215-223.

24. Murakami K and Sasaki S. A low-glycemic index and -glycemic load diet is associated with not only higher intakes of micronutrients but also higher intakes of saturated fat and sodium in Japanese children and adolescents: the National Health and Nutrition Survey. Nutrition Research. 2018; 49:37-47 PubMed .

25. Meng H, Matthan NR, Ausman LM and Lichtenstein AH. Effect of Macronutrients and Fiber on Postprandial Glycemic Responses and Meal Glycemic Index and Glycemic Load Value Determinations. American Journal Clinical Nutrition. 2017; 105 (4): 842-853.

26. Ramdath DD, Isaacs RL, Teelucksingh $S$ and Wolever TM. Glycaemic index of selected staples commonly eaten in the Caribbean and the effects of boiling v. crushing. British Journal of Nutrition. 2004; 91(6):971977.

27. Jayasinghe KWMA, Ekanayake S and Nugegoda DB. Effect of different milling methods on glycaemic responses of foods made with finger millet (Eucenea coracana) flour. Ceylon Medical Journal. 2013; 58(4):148152.
28. Kumar A, Sahu C, Panda PA, Biswal M, Sah RP, Lal MK, et al. Phytic Acid Content May Affect Starch Digestibility and Glycemic Index Value of Rice (Oryza Sativa L.). Journal of Science Food and Agriculture. 2020; 100(4): 1598-1607.

29. Nisanka US and Ekanayake S (2016) Rice variety and processing: contribution to glycaemic response. Ceylon Medical Journal. 2016; 61(4):159-162.

30. Prasad MPR, Rao BD, kalpana K, Rao MV and Patil JV. Glycaemic Index and Glycaemic Load of Sorghum Products. Journal of Science, Food and Agriculture. 2015; 95(8):1626-30.

31. Odenigbo, AM. Nutrient Composition and Predicted Glycemic Index of Rice Varieties from Nigeria. British Journal of Applied Science and Technology. 2014; 4(2):302-318.

32. Rocchetti G, Giuberti G, Gallo A, JBernardi J, Marocco, A, Lucini L. Effect of Dietary Polyphenols on the in Vitro Starch Digestibility of Pigmented Maize Varieties under Cooking Conditions. Food Research International. 2018; 108: 183-191 PubMed .

33. Atkinson FS, Foster-Powell $\mathrm{K}$ and Brand-Miller. International Tables of Glycemic Index and Glycemic Load Values: 2008. Diabetes Care. 2008; 31(12): 2281 2283.

34. Mattei J, Malik V, Wedick NM, Hu FB, Spiegelman $\mathrm{D}$, Willet WC et al. Reducing the global burden of type 2 diabetes by improving the quality of staple foods: The Global Nutrition and Epidemiologic Transition Initiative. Global Health. 2015; 11, 23.

35. Ebere RA, Imungi JK and Kimani VN. Glycemic responses of stiff porridge (ugali) meals consumed in Western Kenya. Food Science and Quality Management. 2017; 63: 55-63.

36. FAO/Government of Kenya. Kenyan Food Recipes. A recipe book of common mixed dishes with nutrient value. Nairobi, FAO. 2018; 349 pp. http://www. fao.org/3/I8897EN/I8897en.pdf.

37. Ofwona AC (2013). An analysis of the patterns of food consumption among households in Kenya. Journal of Emerging Trends in Economics and Management Sciences; 4(1):111-113.

38. Wanjala G, Onyango A, Makayoto M and Onyango C. Indigenous technical knowledge and formulations of thick (ugali) and thin (uji) porridges consumed in Kenya. African Journal of Food Science. 2016;10:385-396.

39. Lovegrove A, Edwards CH, DeNoni I, Patel H, El SN, Grassby T, Zielke C, et al. Critical Reviews in Food Science and Nutrition. 2017; 57(2):237-253.

40. Mlotha V, Mwangwela AM, Kasapila W, Siyame EWP and Masamba K. Glycemic responses to maize 
flour stiff porridges prepared using local recipes in $\mathrm{Ma}$ lawi. Food Science and Nutrition. 2016; 4(2): 322-328.

41. Muthee MW., Anyango JO and Matofari JW. Effect of Processing Methods and Variety on Nutritional Quality of Ready-To-Eat Potato (Solanum tuberosum L.) Products; A Review. Egerton University Conferences Portal, $13^{\text {th }}$ International Conference. 2020. https:// ntc.egerton.ac.ke/_conference/index.php/eu_conference/13th_conference_2019/paper/viewPaper/224.

42. Widanagamage R, Ekanayake $\mathrm{S}$ and Welihinda J. (2013) Effect of extent of gelatinization of starch on the glycaemic responses of carbohydrate rich breakfast meals. Malaysian Journal of Nutrition. 2013; 19(2):233242.

43. Huynh TD, Shrestha AK and Arcot J. Physicochemical Properties and Digestibility of Eleven Vietnamese Rice Starches with Varying Amylose Contents. Food and Function. 2016; 7(8):3599-608.

44. RamyaBai M, Wedick, NM, Shanmugam S, Arumugam K, Nagarajan L, Gunasekaran G, et al. Glycemic Index and Microstructure Evaluation of Four Cereal Grain Foods. Journal of Food Science. 2019; 84(12):3373-3382.

45. Enyiukwu, Dn. Nutritional Significance of Cowpea Leaves for Human Consumption. 2018; doi: 10.15580/ GTFSN.2018.1.061818085.

46. Chikwendu JN, Igbatim AC and Obizoba IC. Chemical Composition of Processed Cowpea Tender Leaves and Husks. International Journal of Scientific and Research Publications. 2014; 4(5): 712-16.

47. Yadav C, Manjrekar PA, Agarwal A, Ahmad A, Hegde A, Srikantiah RM. Association of Serum Selenium, Zinc and Magnesium Levels with Glycaemic Indices and Insulin Resistance in Pre-diabetes: A Cross-Sectional Study from South India. Biological Trace Elements Research. 2017; 175 (1): 65-71.

48. Amoako DB and Awika JM. Polymeric Tannins Significantly Alter Properties and in Vitro Digestibility of Partially Gelatinized Intact Starch Granule. Food Chemistry. 2016; 208: 10-7 PubMed .

49. Cutler DA, Pride SM, Cheung AP. Low intakes of dietary fiber and magnesium are associated with insulin resistance and hyperandrogenism in polycystic ovary syndrome: A cohort study. Food Science and Nutrition. 2019; 7(4):1426-1437.

50. Kim Y, Keogh JB and Cliften PM. Consumption of Red and Processed Meat and Refined Grains for 4weeks Decreases Insulin Sensitivity in Insulin-Resistant Adults: A Randomized Crossover Study. Metabolism. 2017; 68: 173-183 PubMed .

51. Chepngetich I. Effect of Kenyan Finger Millet and White Maize Flours on Postprandial Glycemic Response in Healthy Individuals. Journal of Health, Medicine and Nursing. 2016; 32:18-22.

52. Zhao L, Huan J, Man J, Huai H, Chen Y and Wei C. Physicochemical Properties of Euryale Ferox Kernel Starches from Two Different Regions. International Journal of Food Properties. 2015; 19.150414051301001. 10.1080/10942912.2015.1015733.

53. Fatema K, Rahman F, Sumi N, Kobura K and Ali L. Glycemic and insulinemic responses to commonly consumed potatoes in Bangladeshi type 2 diabetic subjects. European Journal of Food Research and Review. 2011; 1(2):52-60.

54. Jiang, H, Hettiararchchy NS and Horax R. Physical properties and estimated glycemic index of protein-enriched sorghum based chips. Journal of Food Science and Technology. 2018; 55(3):891-898.

55. Schuchardt JP, Wonik J, Bindrich U, Heinemann M, Kohrs H, Schneider I, et al. Glycemic index and microstructure analysis of a newly developed fiber enriched cookie. Food and Function. 2016; 7(1):464-474.

56. Dos Santos LM, Tulio LT, Campos LF, Dorneles $\mathrm{MR}$ and Krüger $\mathrm{CCH}$. Glycemic response to carob (ceratonia siliqua L) in healthy subjects and with the in vitro hydrolysis index. Nutricion Hospitalaria. 2014; 31(1):482-487.

57. Damián-Medina K, Salinas-Moreno Y, MilenkovicD, Figueroa-Yáñez L, Marino-Marmolejo E, Higuera-Ciapara I, et al. In silico analysis of antidiabetic potential of phenolic compounds from blue corn (Zea mays L.) and black bean (Phaseolus vulgaris L.), Heliyon. 2020; 6(3):e03632.

58. Brummer Y, Kaviani M and Tosh SM. Structural and functional characteristics of dietary fibre in beans, lentils, peas and chickpeas. Food Research International. 2014; 67:117-125.

59. Bahado-Singh PS, Riley CK, Wheatley AO, Lowe HI. Relationship between Processing Method and the Glycemic Indices of Ten Sweet Potato (Ipomoea batatas) Cultivars Commonly Consumed in Jamaica. Journal of Nutrition and Metabolism; 2011:584832.

60. Gao H, Cai J, Han W, Huai H, Chen Y and Wei C. Comparison of starches isolated from three different trapa species. Food Hydrocolloids. 2014; 37:174-181. 